\title{
A minimally invasive first stage of ALPPS for hepatoblastoma in a child
}

\author{
Dmitry Akhaladze ${ }^{1}$, Natalia Uskova ${ }^{1}$, Gavriil Rabaev ${ }^{1}$, Denis Kachanov ${ }^{2}$, and Nikolay Grachev ${ }^{1}$ \\ ${ }^{1}$ Departments of Oncology and Pediatric Surgery of Dmitry Rogachev National Research Center of Pediatric \\ Hematology, Oncology and Immunology, ${ }^{2}$ Department of Clinical Oncology of Dmitry Rogachev National Research \\ Center of Pediatric Hematology, Oncology and Immunology, Moscow, Russia
}

\begin{abstract}
Large and giant tumors, especially hepatoblastomas, are more frequently presented in pediatric patients. At about two-third of hepatoblastomas at the time of diagnosis are unresectable and liver transplantation is considered as a treatment of choice because of insufficient future liver remnant volume. In selected cases, 2-staged hepatectomy may be the unique chance for curative resection except hepatectomy followed by liver replacement. Despite the overwhelming spread of minimally invasive liver surgery, the laparoscopic approach remains uncommon in children. A case of successful partial associating liver partition with portal vein ligation for staged hepatectomy firstly accomplished pure laparoscopically on the first stage in an infant is presented. Described experience suggests both: the feasibility of laparoscopic procedures and the effectiveness of partial in situ liver splitting to reach appropriate future liver remnant volume and to avoid liver transplantation and its disadvantages. (Ann Hepatobiliary Pancreat Surg 2020;24:352-356)
\end{abstract}

Key Words: Mini ALPPS; Laparoscopic ALPPS; Children

\section{INTRODUCTION}

In brief, the history of the development of the Associating liver partition and portal vein ligation for staged hepatectomy looks as follows. In $2007 \mathrm{H}$. Schlitt performed the first in situ split in perihilar cholangiocarcinoma patient. ${ }^{1,2}$ After what this technique was developed and since 2012 when Schnitzbauer et al. ${ }^{3}$ introduced the ALPPS (Associating liver partition and portal vein ligation for staged hepatectomy) procedure to avoid the posthepatectomy liver failure after major liver resection, the in situ split became a popular method in liver surgery for adults. To reduce well-known disadvantages and morbidity several modified techniques of the $1^{\text {st }}$ stage were proposed. Among them: associating liver tourniquet and portal ligation for staged hepatectomy (ALTPS), ${ }^{4}$ "hybrid ALPPS" (parenchymal transection in the first stage and portal vein embolization 1 day later), ${ }^{5}$ partial ALPPS (p-ALPPS) implying the transection of $50-80 \%$ of liver parenchyma during the stage $1^{6}$ and others. Besides, a laparoscopic ${ }^{7,8}$ and robotic $^{9}$ the first stage of ALPPS were also introduced. ${ }^{10}$

Contrary, in the pediatric population this procedure develops less rapidly and the first case of this procedure was reposted by Chan et al. ${ }^{11}$ in August 2014.

The case of successful pure laparoscopic $1^{\text {st }}$ stage partial ALPPS followed by extended right hepatectomy in a child is described below. To the best of our knowledge this is the first report dedicated to minimally invasive in situ splitting in a pediatric patient.

\section{CASE}

A 1 year 8 months girl admitted to our hospital with upper abdominal distension. The body weight and height were $11.5 \mathrm{~kg}$ and $79.6 \mathrm{~cm}$, respectively. The serum $\alpha$-fetoprotein level reached $1326 \mathrm{ng} / \mathrm{ml}$. The computed tomography $(\mathrm{CT})$ revealed a huge liver mass measuring $76 \times$

Received: January 9, 2020; Revised: May 31, 2020; Accepted: June 7, 2020

Corresponding author: Dmitry Akhaladze

Departments of Oncology and Pediatric Surgery of Dmitry Rogachev National Research Center of Pediatric Hematology, Oncology and Immunology, 1 Samory Mashela str., Moscow 117997, Russia

Tel: +7-905-587-89-92, Fax: +7-495-664-70-90, E-mail: d.g.akhaladze@gmail.com

Copyright (C) 2020 by The Korean Association of Hepato-Biliary-Pancreatic Surgery

This is an Open Access article distributed under the terms of the Creative Commons Attribution Non-Commercial License (http://creativecommons.org/ licenses/by-nc/4.0) which permits unrestricted non-commercial use, distribution, and reproduction in any medium, provided the original work is properly cited. Annals of Hepato-Biliary-Pancreatic Surgery • pISSN: 2508-5778 - eISSN: 2508-5859 
$130 \times 102 \mathrm{~mm}$, originating from hepatic segments $4 \mathrm{a}, 5,7$, 8 , invading the paracaval portion and caudate process of segment 1 and with no signs of tumor spread on the inferior vena cava (IVC), portal vein bifurcation, abdominal cavity and lymphadenopathy (Fig. 1). On the chest CT, a $3.2 \mathrm{~mm}$ lesion in the right lung segment 6 was detected. The fine-needle liver tumor biopsy confirmed the fetal-epithelial type hepatoblastoma. The metastasis of hepatoblastoma was proved after thoracoscopic removal of the right lung lesion. Thus, the diagnosis of hepatoblastoma PRETEXT III, C1E0F0H0N0P0V0M1 was confirmed. Due to the presence of lung metastasis, the patient was stratified to the very high risk and received adjuvant chemotherapy according to the SIOPEL-4 protocol. $^{12}$ After systemic chemotherapy was finished, the serum $\alpha$-fetoprotein level decreased to $779 \mathrm{ng} / \mathrm{ml}$. CT before surgery showed tumor volume decrease on $65 \%$, but extended right hepatectomy was still considered as a procedure of choice. Future liver remnant (FLR) volume (Couinaud segments 2,3 and a Spiegel lobe of the caudate

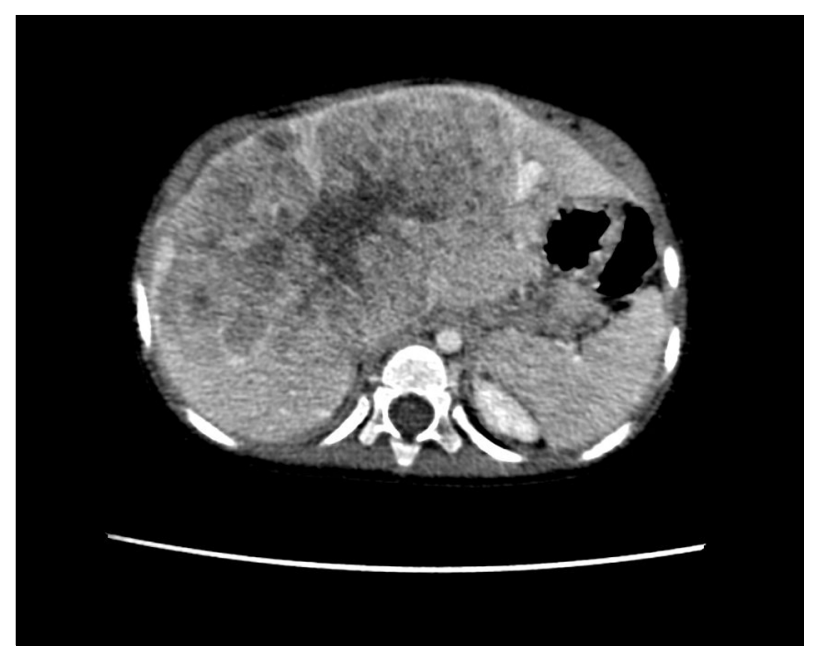

Fig. 1. Initial CT, showing the tumor, involving $4,5,7,8$ and 1 hepatic segments.
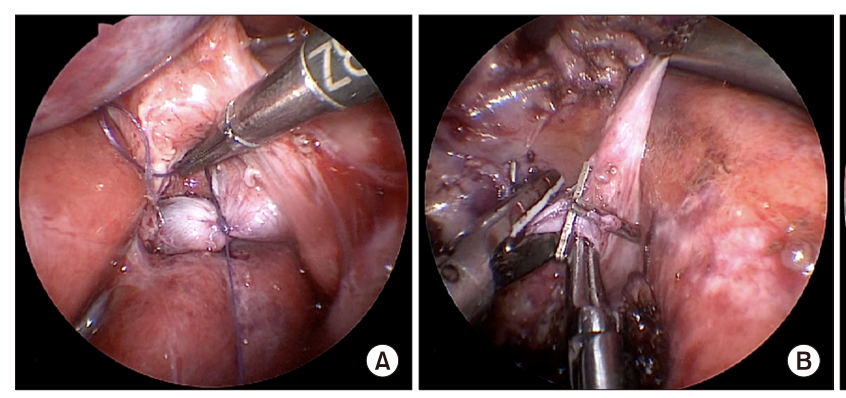

lobe) came to $110.6 \mathrm{~cm}^{3}$ with FLR/SLV (standard liver volume) ratio of $20.5 \%$, thus the decision was made to perform ALPPS using a laparoscopic approach for the first stage of the procedure to rich the appropriate FLR volume.

\section{$1^{\text {ST }}$ STAGE OF ALPPS}

Six 5- mm trocars were placed in the abdominal cavity. Portal vein ligation and partial (75-80\%) liver parenchyma transection using ultrasound destructor and bipolar coagulation along the left border of the umbilical fissure with deportalisation of segment 4 was accomplished totally laparoscopically (Fig. 2). Hepatic arterial inflow, bile duct and venous drainage of the right liver were retained. To expose the right portal vein, the gallbladder was not removed, as well as no plastic film was used to separate the future specimen. At the end of procedure 1 drain was placed in the area of liver bipartition. The Pringle maneuver during parenchyma transection was applied for 24 min. Operation time was $248 \mathrm{~min}$ and estimated blood loss came to $50 \mathrm{ml}$.

The postoperative course after the first stage was uneventful. Oral intake recommenced the next day after surgery. CT-volumetry on a postoperative day (POD) 6 showed the increase of FLR volume to $33 \%\left(188.7 \mathrm{~cm}^{3}\right)$. The second stage was completed on the same day because on the CT partial intestinal wall strangulation in the trocar site was suspected.

\section{$2^{\mathrm{ND}}$ STAGE OF ALPPS}

The procedure started with bisubcostal incision. The abdominal cavity revision and intraoperative ultrasonography confirmed preoperative findings and verified the left border of the tumor. The strangulated intestinal loop was
Fig. 2. (A) Ligated right portal vein. (B) Dissection of S4 portal branches. (C) Liver parenchymal transection. 
not critically damaged and did not require any intervention. The drain was removed and the right liver was mobilized. 6 short veins from posterior section dissection allowed mobilizing and encircling of right hepatic vein (RHV). The right hepatic artery was divided first between ligatures followed by completion of parenchymal transection without intermittent hepatic vascular occlusion. As transection was completed, the hilar plate, containing the right hepatic duct and S4 bile duct was divided sharply. The middle and right hepatic veins were dissected out and the specimen containing the right liver with caudate process, paracaval portion of caudate lobe and segment 4 were then removed. The "white-test" was applied and the common and left hepatic ducts were drained due to a $1 \mathrm{~mm}$ defect in the left hepatic duct (Fig. 3). The abdominal wall was closed. Operation time was $316 \mathrm{~min}$ and blood loss came to $300 \mathrm{ml}$.

The bile duct tube was removed on the $24^{\text {th }}$ day of the uneventful postoperative course. The signs of posthepatectomy liver failure were not observed. The patient was discharged on POD 14 and the adjuvant chemotherapy started on time. Final histopathology confirmed initial diagnosis and clear surgical margins.

Currently, the disease-free and event-free survival is up to 15 months. The follow-up CT 6,12 and 15 months after surgery have shown no evidence of recurrence, as well

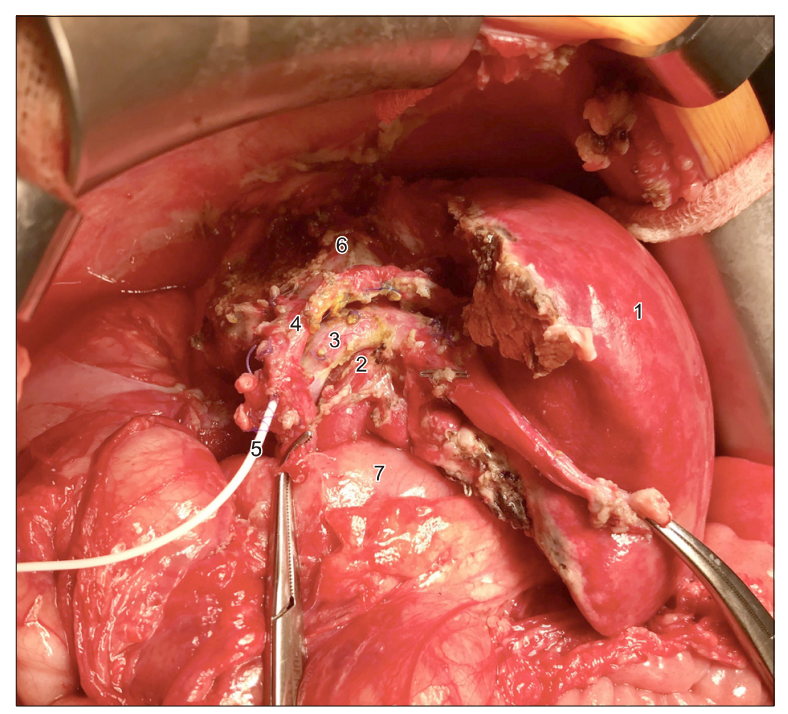

Fig. 3. The extended right hepatectomy is completed. 1, remnant liver; 2, left hepatic artery; 3, left portal vein; 4, left hepatic duct; 5 , biliary drainage; 6 , inferior vena cava; 7 , duodenum. as the serum $\alpha$-fetoprotein level remains stable.

\section{DISCUSSION}

Due to the embryonic origin and fast growth, pediatric liver tumors, especially hepatoblastomas, are more frequently presented large or even giant-sized. A large number of hepatoblastomas at the time of diagnosis are unresectable and liver transplantation is considered as a treatment of choice because of insufficient future liver remnant volume. In selected cases, 2-staged hepatectomy may be a unique chance for curative resection. At the same time, not all of the existing well-known varieties of two-stage liver resections can be used in combined treatment of hepatoblastoma in childhood. For instance, following portal vein embolization during the first stage, proper FLR hypertrophy takes at least 3 weeks. Similarly, portal vein ligation on the first stage does not enable the liver volume to increase in the shortest time. Thus, the most attractive technology, allowing to achieve a sufficient FLR volume as soon as possible is the ALPPS procedure. Despite this, compared with portal vein embolization and ligation, ALPPS, especially it's $1^{\text {st }}$ stage remains the most traumatic intervention and is associated with severe complications that can disrupt the chemotherapy timing. From this point of view, the minimization of surgical trauma of the first stage seems to be most

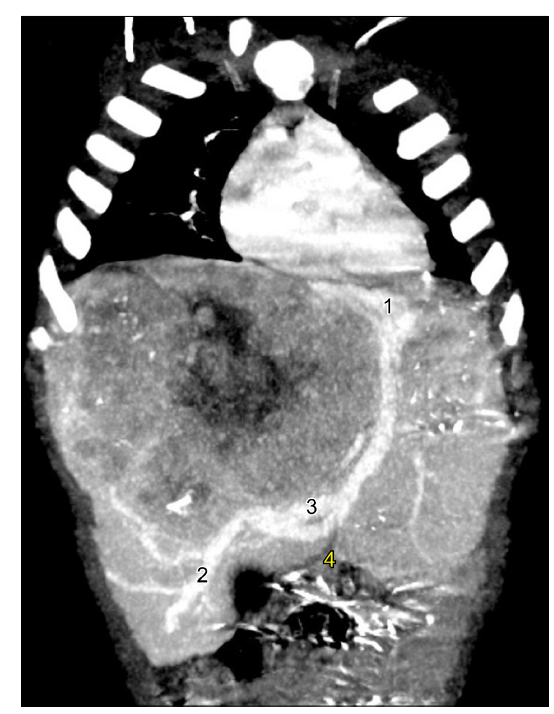

Fig. 4. The CT before $2^{\text {nd }}$ stage surgery. 1, left hepatic vein; 2 , distal right hepatic vein; 3 , shunt between right and left hepatic veins; 4 , umbilical fissure. 
justified.

In 2017, Hong et al. ${ }^{13}$ have reported the first experience of partial liver splitting at the first stage of ALPPS in pediatrics. On the POD 7 the increase in the FLR volume came to $13.3 \%$, reaching the FLR/SLV ratio of $38 \%$. In the current observation, the hypertrophy of segments 2,3 and 1 to $33 \%$, sufficient to prevent the posthepatectomy liver failure was achieved with partial liver bipartition in 6 days and the liver remnant volume increase came to $12.5 \%$. Undoubtedly, following the complete liver parenchymal transection, the increase in the volume of the liver remnant could reach larger values, however, the decision was made to perform partial resection due to the presence of a large venous shunt between right and left hepatic veins, located in the umbilical fissure (Fig. 4).

The laparoscopic liver resections in adult patients develop during more than two decades and its feasibility and safety are proved. ${ }^{14}$ Although it is widely spread and the first European Guidelines Meeting on Laparoscopic Liver Surgery (EGMLLS) was held in Southampton in 2017, and guidelines for laparoscopic liver surgery were validated, the experience and literature in children in this field remains scarce. ${ }^{15}$ The current case report depicts the feasibility and advantages of minimally invasive approach on the $1^{\text {st }}$ stage of ALPPS procedure and the fast recovery between two surgical interventions.

\section{CONCLUSION}

This is the $6^{\text {th }}$ report of the ALPPS procedure, ${ }^{11,16-18}$ the $2^{\text {nd }}$ case of partial liver splitting and the $1^{\text {st }}$ case of pure laparoscopic $1^{\text {st }}$ stage ALPPS in a child. ${ }^{13}$ The described observation proves the feasibility of the laparoscopic approach for pediatric liver surgery and suggests that partial liver transection during the $1^{\text {st }}$ stage enables an adequate increase of FLR volume. In selected cases ALPPS could be successfully applied and allows to avoid liver transplantation in hepatoblastoma patients, in which giant tumors are more frequently presented.

\section{ACKNOWLEDGEMENTS}

This research did not receive any specific grant from funding agencies in the public, commercial, or not-forprofit sectors.

\section{ORCID}

Dmitry Akhaladze: https://orcid.org/0000-0002-1387-209X

Natalia Uskova: https://orcid.org/0000-0001-9424-1646

Gavriil Rabaev: https://orcid.org/0000-0002-5691-2522

Denis Kachanov: https://orcid.org/0000-0002-3704-8783

Nikolay Grachev: https://orcid.org/0000-0002-4451-3233

\section{REFERENCES}

1. Baumgart J, Lang SA, Lang H. A new method for induction of liver hypertrophy prior to right trisectionectomy: a report of three cases. HPB (Oxford) 2011;13(Suppl 2):71-72.

2. de Santibañes E, Clavien PA. Playing Play-Doh to prevent postoperative liver failure: the "ALPPS" approach. Ann Surg 2012; 255:415-417.

3. Schnitzbauer AA, Lang SA, Goessmann H, Nadalin S, Baumgart J, Farkas SA, et al. Right portal vein ligation combined with in situ splitting induces rapid left lateral liver lobe hypertrophy enabling 2-staged extended right hepatic resection in small-for-size settings. Ann Surg 2012;255:405-414.

4. Robles R, Parrilla P, López-Conesa A, Brusadin R, de la Peña $\mathrm{J}$, Fuster M, et al. Tourniquet modification of the associating liver partition and portal ligation for staged hepatectomy procedure. Br J Surg 2014;101:1129-1134; discussion 1134.

5. Li J, Kantas A, Ittrich H, Koops A, Achilles EG, Fischer L, et al. Avoid "All-Touch" by Hybrid ALPPS to achieve oncological efficacy. Ann Surg 2016;263:e6-e7.

6. Petrowsky H, Györi G, de Oliveira M, Lesurtel M, Clavien PA. Is partial-ALPPS safer than ALPPS? A single-center experience. Ann Surg 2015;261:e90-e92.

7. Machado MA, Makdissi FF, Surjan RC. Totally laparoscopic ALPPS is feasible and may be worthwhile. Ann Surg 2012;256: e13; author reply e16-e19.

8. Conrad C, Shivathirthan N, Camerlo A, Strauss C, Gayet B. Laparoscopic portal vein ligation with in situ liver split for failed portal vein embolization. Ann Surg 2012;256:e14-e15; author reply e16-e17.

9. Vicente E, Quijano Y, Ielpo B, Fabra I. First ALPPS procedure using a total robotic approach. Surg Oncol 2016;25:457.

10. Cai YL, Song PP, Tang W, Cheng NS. An updated systematic review of the evolution of ALPPS and evaluation of its advantages and disadvantages in accordance with current evidence. Medicine (Baltimore) 2016;95:e3941.

11. Chan A, Chung PH, Poon RT. Little girl who conquered the "ALPPS". World J Gastroenterol 2014;20:10208-10211.

12. Zsiros J, Brugieres L, Brock P, Roebuck D, Maibach R, Zimmermann A, et al; International Childhood Liver Tumours Strategy Group (SIOPEL). Dose-dense cisplatin-based chemotherapy and surgery for children with high-risk hepatoblastoma (SIOPEL-4): a prospective, single-arm, feasibility study. Lancet Oncol 2013;14:834-842.

13. Hong JC, Kim J, Browning M, Wagner A, Lerret S, Segura AD, et al. Modified associating liver partition and portal vein ligation for staged hepatectomy for hepatoblastoma in a small infant: how far can we push the envelope? Ann Surg 2017;266:e16-e17.

14. Moisan F, Gayet B, Ward MA, Tabchouri N, Fuks D. Segment 7 laparoscopic liver resection: is it possible to resect when metastatic lesions border suprahepatic veins? J Gastrointest Surg 2018;22:1643-1644. 
15. Abu Hilal M, Aldrighetti L, Dagher I, Edwin B, Troisi RI, Alikhanov R, et al. The Southampton Consensus Guidelines for Laparoscopic Liver Surgery: from indication to implementation. Ann Surg 2018;268:11-18.

16. Wiederkehr JC, Avilla SG, Mattos E, Coelho IM, Ledesma JA, Conceição $\mathrm{AF}$, et al. Associating liver partition with portal vein ligation and staged hepatectomy (ALPPS) for the treatment of liver tumors in children. J Pediatr Surg 2015;50:1227-1231.
17. Xu ZL, Wang L, Fan W, Hao ZH, Li C. ALPPS for hepatic mesenchymal hamartoma in an infant. J Pediatr Surg Case Rep 2018;37:70-73.

18. Qazi AQ, Syed AA, Khan AW, Hanif F. Early multifocal recurrence of hepatoblastoma in the residual liver after R0 liver resection with ALPPS procedure: a case report. Ann Transl Med 2016;4:375. 